\title{
Tree Sampling in Natural Forests of Northern Iran ${ }^{1}$ by \\ M. Zobeiry
}

\section{Research Note}

\begin{abstract}
The 6-tree sampling method which was introduced in 1969 by Dr. Prodan was tested by the Faculty of Natural Resources at the University of Tehran in the natural forests of Northern Iran. Variations including 6-, 7-, 8- and 9-tree sampling were examned. The research shows that the tree sampling technique is not suitable for the natural forests of the northern region. Each of the 6-, 7-, 8- and 9-tree systems consistently underestimates the true population parameters.
\end{abstract}

\section{Introduction}

In 1968, Dr. Prodan introduced a new sampling system called 6-tree sampling. (1) His theoretical proposals were followed quickly in 1969 by practical experimental applications in forest management. Both field and computer simulation experiments indicated that 6-tree sampling had potential for forest management. $(2,3)$ It has several advantages. Field work requires only a 2-man crew, it is easy to measure trees selected at sampling points, and the area of the sample is dependent on stand density.

Because of these advantages the Faculty of Natural Resources at the University of Tehran decided to test this sampling method in the natural forests of Northern Iran. Variations, including 6-, 7-, 8- and 9-tree sampling, were tested in a known population and compared with other sampling techniques commonly used in forestry. The objective was to find the most efficient sampling method for Iranian forests.

\section{What Is 6-Tree Sampling?}

Simply stated, 6-tree sampling means that each sample plot consists of the six trees closest to sample center. Measurements made on these plots include diameter at breast height to the nearest centimeter for each of the 6 trees and distance from sample centre to the 6 th most distant tree.

1. This research has been done with financial help of the University of Tehran (Iran).

2. Associate professor in College of Natural Resources, University of Tehran and visiting associate professor in Faculty of Forestry, University of British Columbia.

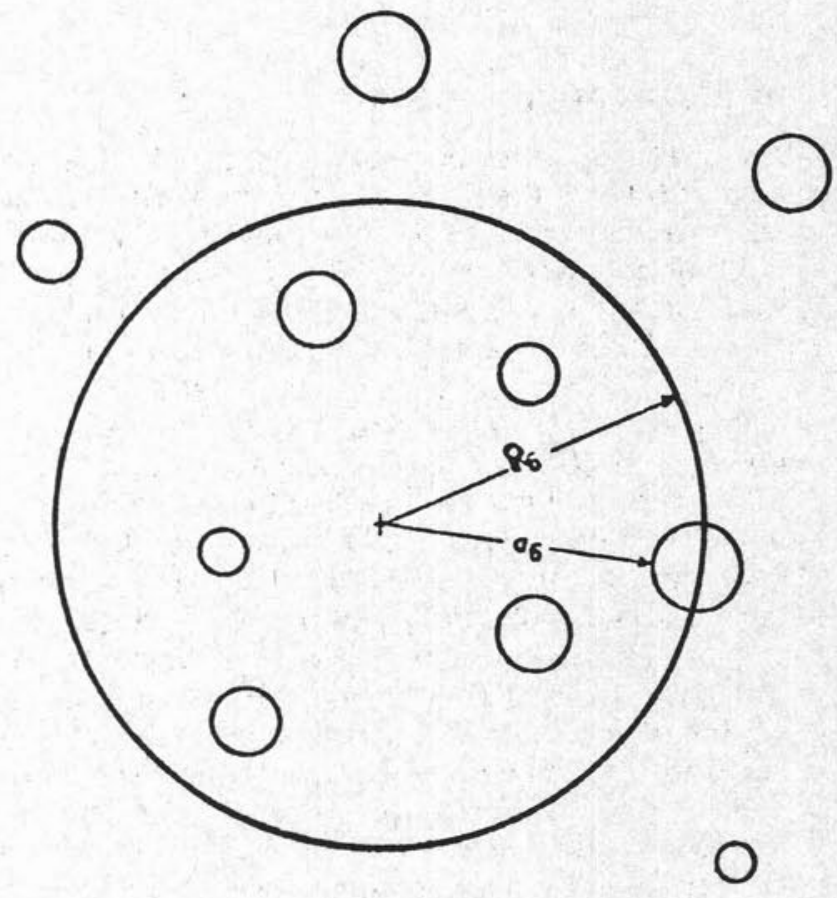

Fig. 1. The 6-tree sample plot

The radius of such a sample plot would be

$R_{6} a_{6}+1 / 2 d_{6}$ where $R_{6}=$ radius of the sample plot, (in $\mathrm{cm}$.) $\mathrm{a}_{6}=$ distance from the sample centre to (in $\mathrm{cm}$.) 6 th tree, and $d_{6}$ is the diameter at breast height of the 6 th tree.

If the diameters of the six trees are $d_{1}, d_{2}, d_{3}, d_{4}, d_{5}$ and $d_{6}$, the basal area can be estimated for all trees on a hectare by the following formula:

$$
\begin{aligned}
& \mathrm{G} / \mathrm{ha}=\frac{10000}{\pi \mathrm{R}_{6}^{2}} \times \frac{\pi}{4}\left(\mathrm{~d}_{1}^{2}+\mathrm{d}_{2}^{2}+\ldots 1 / 2 \mathrm{~d}_{6}^{2}\right) \\
& O R=\frac{2500}{\mathrm{R}_{6}^{2}}\left(\mathrm{~d}_{1}^{2}+\mathrm{d}_{2}^{2}+\ldots 1 / 2 \mathrm{~d}_{6}^{2}\right)
\end{aligned}
$$

The average basal area per hectare for the entire forest can be estimated from

$$
\begin{gathered}
\mathrm{G} / \mathrm{hec}=\frac{\mathrm{G}_{1} \times \mathrm{F}_{1}+\mathrm{G}_{2} \times \mathrm{F}_{2}+\ldots \mathrm{G}_{\mathrm{i}} \mathrm{F}_{\mathrm{i}}}{\Sigma \mathrm{F}_{\mathrm{i}}} \\
\mathrm{i}=1 \ldots \mathrm{n}
\end{gathered}
$$




\begin{tabular}{|c|c|c|c|c|c|c|c|}
\hline \multirow[b]{2}{*}{ Kind of Sampling } & \multirow[b]{2}{*}{$\mathbf{N}$} & \multirow[b]{2}{*}{$\overline{\mathbf{G}} / \mathbf{m}^{2}$} & \multirow[b]{2}{*}{$\mathbf{S}$} & \multirow[b]{2}{*}{$\mathbf{G}_{\mathbf{G}}$} & \multirow[b]{2}{*}{$\mathbf{S}_{\mathbf{G}}^{\overline{\mathbf{S}}}$} & \multicolumn{2}{|c|}{ Difference } \\
\hline & & & & & & $\mathbf{N} \%$ & G \% \\
\hline $\begin{array}{l}\text { 6-tree sampling } \ldots \ldots \ldots \ldots \ldots \ldots \ldots \\
\text { 7-tree sampling } \ldots \ldots \ldots \ldots \ldots \ldots \ldots \\
\text { 8-tree sampling. } \ldots \ldots \ldots \ldots \ldots \ldots \ldots \\
\text { 9-tree sampling } \ldots \ldots \ldots \ldots \ldots \ldots\end{array}$ & $\begin{array}{l}280 \\
281 \\
288 \\
283\end{array}$ & $\begin{array}{l}33.31 \\
33.14 \\
32.97 \\
31.82\end{array}$ & $\begin{array}{l}26.8 \\
18.5 \\
17.7 \\
14.1\end{array}$ & $\begin{array}{l}80.5 \% \\
55.9 \% \\
53.6 \% \\
44.3 \%\end{array}$ & $\begin{array}{l}3.46 \\
2.39 \\
2.28 \\
1.82\end{array}$ & $\begin{array}{l}-22 \\
-21 \\
-19 \\
-21\end{array}$ & $\begin{array}{l}-6 \\
=7 \\
=7 \\
-10\end{array}$ \\
\hline Known parameters. & 357 & $\mu=35.52$ & $\sigma=14.24$ & $40.1 \%$ & - & & \\
\hline
\end{tabular}

where $G$ and $F$ are the basal area per hectare of the trees in each plot and the area of each sample plot respectively.

The volume per hectare can be calculated with the aid of local volume equations and stand form factors.

\section{The Experimental Area}

An area 60 hectares was selected in the research forest of the Faculty of Natural Resources of the University of Tehran (Iran) in North Iran which lay between 400 and $700 \mathrm{~m}$ above sea level with a northern aspect. Slopes ranged from 10$70 \%$. The forest is a natural mixed forest consisting of about $56 \%$ birch (Carpinus betulus), $29 \%$ beech (Fagus orintalis) and 15\% other species such as elm (Ulmus Sp.) and maple (Acer Sp.). Rainfall ranges between 1200 and $1400 \mathrm{~mm}$. per year. The entire 60 hectares was divided into 960 square sample sub-units, the size of each square sample plot being $625 \mathrm{~m}^{2}(25 \mathrm{~m}$ by $25 \mathrm{~m})$. In each subsample plot the DBH of all trees larger than $6.5 \mathrm{~cm}$ at $1.3 \mathrm{~m}$ above the ground was measured for diameter in $1 \mathrm{~cm}$ classes. Each tree was numbered and permanently tagged. As various sampling experiments were carried out in this area, further diameter measurements were not needed, only tree number was recorded to eliminate systematic errors and bases which could occur from faulty measurements of diameter. A total of 21,410 trees was measured. This $100 \%$ sampled area became the basis for numerous sampling experiments following its establishment.

For this particular experiment the centre of each hectare was chosen to be a sample centre for 6-, 7-, 8- and 9-tree sampling. Numbers of tree numbers within each plot were recorded from the original DBH list as each sample was established.

\section{Analysis and Results}

All the data were analyzed with the aid of a computer program provided by Dr. Bergel of West Germany on an IBM 370 Model 135 computer at the University of Tehran. For each of the 6-, 7-, 8and 9-tree sampling systems the following information was calculated.

$$
\begin{array}{ll}
\mathrm{N} & =\text { average numbers of trees per hectare } \\
\overline{\mathrm{G}} / \mathrm{m}^{2} & =\text { average basal area per hectare } \\
\mu & =\text { true basal area of the population per } \\
& \text { hectare }
\end{array}
$$

$\mathrm{S}$

$\sigma \quad=$ known standard deviation of the population

$\mathrm{C}_{\mathrm{G}} \quad=$ coefficient of variation

$\mathrm{N} \%=$ difference from the true mean for number of trees per hectare

$\overline{\mathrm{G}} \%=$ difference from true mean $(\mu)$ for basal area per hectare

$\mathrm{S}_{\overline{\mathrm{G}}} \quad=$ standard error of the mean for the sampling system.

Analysis of variance tests show that there is no significant difference between average basal area per hectare and true basal area for 6-, 7- and 8tree sampling systems but there is a significant difference between the results obtained for 9-tree sampling system and the true population value. The number of trees, however, was significantly different for all sampling procedures and showed consistent underestimations ranging from $-19 \%$ to $-22 \%$.

\section{Conclusions}

This research shows that the tree sampling technique is not suitable for the natural forests of northern Iran. Each of the 6-, 7-, 8- and 9-tree systems consistently underestimates the true population parameters. Research results of Ko, Thiry, Pelz, Ehrlenspiel (2) also showed significant negative biases ranging up to $6.7 \%$ for basal area. It is possible that the clumped structure of the natural forests of Northern Iran, which are partly all-aged, may contribute to the negative bias. In some places mixtures of young and old, small and large trees results in unusually large coefficients of variation, i.e. $81 \%$ for a 6 -tree sampling system. Shopfer (3) suggests that there may be unknown procedural errors, for example, trees with some parts of stems, i.e. less than half in a sample plot, are not considered. It is also possible the results of this study may be biased as a result of an insufficient number of sample plots. Prodan (1) indicates a need for approximately 4 to 6 sampling points per hectare for the 6-tree sampling system, which is far too intensive and not practicable for the natural forests of Northern Iran.

\section{References}

1. Prodan, M., 1968: Punktstichprobe fur die Forteinrichtung, FoHo., H.11.

2. Ko, Thiry, Pelz, Ehrlenspiel, 1969: 6-Baum-stichprobe fur die Forsteinrichtung, AFJZ, 140.

3. Shopfer, W., 1969: Die 6-Baum stichprobe in der Forsteinrichtung Allgemeine Forstzeitschrift Nr. 26 und 29. 